\title{
The glossary of the ancient Chinese vocabulary in Longdong-dialect
}

\author{
Guo Jianhua ${ }^{1}$, Wang Jinxiao ${ }^{1, b}$ \\ ${ }^{1}$ Longdong college Gansu Qingyang 745000 \\ bIdxywjx@126.com
}

Keywords: Longdong dialect, vocublary of ancient Chinese vocabulary, significance and glossary. Abstract. In this paper, we summarized and recorded part of ancient Chinese vocabulary frequently used in Longdong-dialect mainly through field investigation, which not only revealed the true nature of Longdong dialect, but also facilitated the in-depth study of Longdong dialect at phonological level, conducive to exploring the cultural significance of folk customs in Longdong area.

\section{Introduction}

People living in the east region of Gansu Province still use a lot of place names and dialects, as well as keeping folklores from Zhou, Qin, Han and Tang Dynasties, which are considered as living fossils of northern Mandarin dialects and folks, and play an important role in Chinese language culture history. In this paper, we summarized and recorded part of ancient Chinese vocabulary frequently used in Longdong-dialect mainly through field investigation, which not only revealed the true nature of Longdong dialect, but also facilitated the in-depth study of Longdong dialect at phonological level, conducive to exploring the cultural significance of folk customs in Longdong area. The glossary is as follows:

Han:a rain which lasts for long time. For example, “Han” refers to a rain lasting for long tine in the Origin of Chinese Characters.

Cha: cutting horizontally or obliquely. For instance, Cha means cutting and chopping in the Origin of Chinese Characters.

Choke: throat is obstructed by something such as dry bread. For example "Felling depressed like the throat is chocked by food” in the Book of Songs Wang Feng Shuli.

Tang: a bar supporting human legs between desk leg or chair leg, including desk bar and bed bar. It refers to a bar in the Origin of Chinese Characters.

Mi: entering into or attaching to something. For instance: the earth enters into eyes. It denotes grass entering into eyes in the Origin of Chinese Characters.

Yong: withered or listless. For example, the sun withers the leaves of crops. It represents laziness in the Origin of Chinese Characters.

Gu: the first birthday of a kid, which refers to first birthday after birth in the Origin of Chinese Characters.

Zhun: something pure and real, such as real Red Fuji Apple. The word is mentioned in the Eight Volume of the Three Kingdoms.

Hou: food "Hou" refers to "corn powder bread", such as: "sticky corn powder bread." The Book of Songs Daya Gongliu mentioned dried corn powder bread, and the Origin of Chinese Characters explained "Hou" as dried food.

Zui: bump or swelling, or male genitalia, such as a bump on growing on the arm. It refers to male genitalia in the Origin of Chinese Characters.

Liao: open space outside a house, such as open (outdoor) place. The Origin of Chinese Characters explaines it as empty place.

Xiao: arms and hands, such as long arms. It denotes arm in the Origin of Chinese Characters.

Bian: tucking clothes, for instance, "tucking long sleeves". It means "tucking” in On Balance Self-Discipline.

Yin: reproduction and high yield. For example, high-yielding jujube. In the Origin of Chinese Characters, it refers to carrying on the family line. 
Xia: metal bonds at both ends of wheel axle, currently known as "axle-pins", which evolved to the meaning of "axle-pins" and "taking control of someone, for instance: "the beauty is sitting on the carriage" in the Book Xiaoya Chexia, and "applying oil to axle-pins" in the Beifeng - Spring.

Ju: something obstructed such as an obstructed (blocked) canal. Deserted canal obstructed by wild grass in the Book of Songs Xiaoy Xiaohui.

Pao: long gown, military uniforms in ancient times. It is used as classifier in Longdong dialect with the meaning of "a lot of". It also means keeping up with others to do something. For instance "seeing other children go to school, he also goes to school." It has the same meaning in the Book of Songs Qinfeng Wuyi

Ji: shepherd's purse, a wild herb, also known as "Chesneya nubigena". In the Book of Songs Beifeng Gufeng, 'who said the tea is bitter, it is as sweet as shepherd's purse".

Jin: axe, such as Ping Jin (adze used by a carpenter). In The Origin of Chinese Characters, Jin refers to chopping wood.

Gou: crowing, an onomatopoeia. In the Book of Songs Xiaoya Xiaohui, "pheasant crows in the morning”.

Qie: strong and healthy, such as: "a strong and healthy man." In the Book of Songs Weifeng Shuoren: beefy warrior. In the Note to the Book of Songs by Gao Heng, Qie refers to strong body.

Ji: draging and pulling. When logging a tree, a rope is used to pull the tree trunk to slowly take down the tree. For example, "it is a downhill, drag the carriage from behind." In the Book of Songs Xiaoya Xioahui, “dragging a rope when logging a tree”.

: big object, which gets in the way. For example: penetrating into the sly from the ground. The Origin of Chinese Characters explained it as a horn-shaped object.

Duo: cleaning up and tidying up, for instance: "the work will end soon, put up the things on the table. In the Origin of Chinese Characters, "Duo" also refers to picking, and pick up means "Duo".

Ba: peeling in Longdong dialect, for example: "peeling onion", "peeling garlic" and " skinning". In the Note to the Book of Songs by Cheng Junying, "Ba” represents skinning a sheep.

Cun: thinking carefully and contemplating, for instance: "he is not good at thinking (Cun)". In the Book of Songs Xiaoya Dialect, “doing before carefully thinking”.

Hong: an onomatopoeia, referring to the sound of insects or insect swarm flying by in Longdong dialect, In the Book of Songs Zhounan Long-horned grasshopper: long-horned grasshoppers fly by buzzing. In Qi Feng - Crow: numerous insects fly by.

Yi: planting, which means getting engaged in planting and cultivating in Longdong dialect, for example, training people before planting crops." In the Book of Songs Daya Livelihood, "planting soybeans”.

Rou: rubbed repeatedly by hands or foot, For example: "hurry up, you stamp ants under your shoes to die." In the Book of Songs Daya Livelihood, "stamping or rubbing”.

Yi: killing. For example: "kill him on behalf of me." In the Book of Songs Xiaoya Jiri": kill the oldest son.

Shuang: error or growing shorter, for instance: "this kid hasn't grown taller in a few years, but gets shorter." In the Book of Songs Weifeng Meng: there is nothing wrong with a woman, but the man's behavior is not consistent..

Xiang: windows facing to the north, referring to light and hope. For example, No-Xiang (windows not facing to the north) means no light or hope. For example "I think there is hope, but you disagree with me." "The college entrance examination scores increases, there is no chance for my son to go to college." In the Book of Songs Youfeng July, “closing windows facing to the north”. In the Origin of Chinese Characters, "Xiang" refers to facing to the north, which is You.

Chu: stopping and pausing, for example: stand (stop). In The Origin of Chinese Characters, "Chu" means "stopping".

Tiao: trimming, for example: "take an axe and trim mulberry tree." There is a folk that "good trees do not need to trim and crooked trees cannot be corrected." In the Book of Songs Youfeng July, mulberry tree is trimmed by silkworms. 
Hao: pulling grass, which is used with "Jian” in "Longdong dialect. For example, "before getting ripe, the apricots were picked by childeren." In the Book of Songs Zhou Song Liang Si: pulling out the tea.

Pao: cooking, referring to cooking food in Longdong dialect. For example, "cooking something to eat" and "decocting traditional Chinese medicine". In the Book of Songs Lu Song Secret Palace: cooking soup. In Xiaoya June: "roasting turtle and cooking carp.

Qiong: losing face and being disgraced. For example, "too disgraceful” or "having no shame”. In the Origin of Chinese Characters, "Qiong” means "worries”.

Diao: long time or distance space, for example, long face; walking for long distance. In the Origin of Chinese Characters, "Diao” refers to profoundness.

Pou: making a grave by accumulating soil little by little by hand, which refers to putting things together in Longdong dialect. For example, "putting these odds and ends together." In the Book of Songs Xiaoya Changdi: a place people gather together. In Shang Song - Yin Wu, a trip of capturing Jing people”.

Zhuo: pecking and cutting, for example, "slap him in the face." "cutting grass for cattle." In the Origin of Chinese Characters,"Zhuo" refers to "pecking”.

Mie: slices of bamboo, reed and straw, which can be used to weave. For instance: bamboo strips for weaving and bamboo basket for storing arrows. In the Origin of Chinese Characters. "Mie" is also synonymous to "Tu”,.

Han: washing clothes, for example: "take off your clothes and wash." In the Book of Songs Zhou Nan Getan: rinsing my robes. In the Beifeng Baizhou, it means washing clothes.

Yang: A leather belt leashing horse, such as a "leash". In the Book of Songs Xiaoya Beishan, it refers to "working from morning to night, never stopping to worry for the lords".

Die: biting, for example, “out of guard, I was bitten by a dog”. In the Book of Changes, "stepping the tail of a tiger, it will not bite".

Xin: jealousness and love, which is used together with "Xiang" in Longdong dialect, referring to people with reputation and prestige in the local place. In the Book of Songs Daya Huangyi, "do not get obsessed with fame and fortune”. In Daya Livelihood, "Emperor Wu has good reputation”.

Wan Luan: managing to do something in Longdong dialect, or a man courting a woman. For example, "I will manage to make some money." "He won the love of that woman eventually. The word is mentioned in the Book of Songs Qifeng Futian. In the Qifeng Yijie, it refers to a beautiful woman.

Nie: decaying and rotting. For example, "the firewood gets rotten." In the Analects of Confucius Goods, "people with firm will never go decay".

Da: keeping something in mouth in Longdong dialect, for example, "the amount can be estimated by feeling by mouth, no need to use Abacus." The word is referred in the Book of Songs -Xiaoy- the Turn of the October.

San: homeless people or those who get engaged in bad things. In Zheng Zi Tong, “San” also refers to a castrated rooster, or castrated cattle, hog or horse".

Ma: Ancient Military sacrifice in Horse God Festival, and the witch who wears horns is referred as "horn witch in Longdong dialect. The word is mentioned in the Book of Songs - Emperor.

Qi: the extending part of axle, which also refers to all protruding parts in Longdong dialect, or going too far. For example, "set aside a part when making a dress." "you go too far. In the Book of Song Shangsong Liezu: "axle warped by colorful leather and decorated with beautiful patterns."

Zheng: covered by the soil cover and cleaned up. For examples: "Clean the shack." In the Origin of Chinese Characters, "Zheng” refers to soil.

Er Shi: negation or distrust in Longdong dialect. For instance, "we talked a lot, but they didn't believe what we said." In the Historical records - Chronology of Six Kingdoms, "this is equal to distrust”. 


\section{Acknowledgements}

The article was written for 2016 Gansu Province Education and Science "the 13th Five-Year" Planning "Study on Ancient Chinese Vocabulary in Longdong Dialect" (Project No. GS[2016]GHB1226). In addition, the article was sponsored by Gansu Provincial University Humanities and Social Sciences Base -- Farming Culture and Longdong Folk Culture Industry Development Research Center.

\section{References}

[1] Yao Xuedi. Ancient Chinese Vocabulary in Longdong Dialect [J], Worries, 2014

[2] Guo Jianhua, Glossary of Ancient Chinese vocabulary in the dialect of Ning County [J]. Chinese Journal, 2015

[3] Xu Shen. ShuoWenJieZi Photocopy [M]. Beijing: Zhonghua Book Company, 1963

[4] Editorial Department.of Zhonghua Book Company, Photocopy of the Thirteen Classics [M]. Beijing: Zhonghua Book Company, 1980

[5] Duan Yuacai. ShuoWenJieZi Photocopy [M]. Shanghai: Shanghai bookstore, 1992

[6] Ban Gu (Estern Han dynasty) Han [M]. Beijing: Zhonghua Book Company, 1991

[7] Confucius Extarct. Book of Songs [Z]. Beijing: Beijing Press, 2012

[8] Yang Quan (notes). Book of Chnages[Z]. Nanjing: Southeast University Press, 2013

[9] Wang Chong (Eastern Han Dynasty) Note to ShuoWenJieZi [M].. Shanghai: Shanghai People's Publishing House, 1974

[10] Liu Xi (Eastern Han Dynasty). Ming [M]. Beijing: National Library Press, 2014

[11] Zhang Zilie (Ming Dynasty) and Liao Wenying (Qing Dynasty), Zhengzitong [M]. Beijing: China Personal Press, 1996

[12] Shen Wenjiong [M]. Qingyang dialect words[M], Qingyang Photo Agency, 2000 